\title{
Risk of cardiovascular diseases in seafarers
}

\section{Marcus Oldenburg}

Institute for Occupational and Maritime Medicine (ZfAM), University Medical Center Hamburg-Eppendorf, Germany

\begin{abstract}
Seafarers experience a lot of job-related risk factors for cardiovascular diseases (CVD). Considering the healthy-worker effect due to the biennial pre-employment examination and the periodical medical fitness tests, a (slightly) elevated risk for CVD among seafarers is assumed compared to the reference population ashore. In seafaring, the most important, influenceable risk factors for CVD refer to the ship-specific stress situation, the malnutrition and the lack of exercises on board. Furthermore, the prognosis of acute severe CVD often depends on the measures taken in the first few hours after occurrence of the symptoms. Owing to the lack of health professionals on board and the limited treatment options of events at sea, effective cardio-pulmonary resuscitation is often delayed and the outcome of cardiac events is worse compared to that ashore.
\end{abstract}

(Int Marit Health 2014; 65, 2: 53-57)

Key words: cardiovascular risk, seafarers, shipboard stressors, nutrition on board

\section{INTRODUCTION}

Cardiovascular diseases (CVD) are a leading cause of morbidity and mortality worldwide. Each year CVD causes an estimated 17 million deaths worldwide, accounting for onethird of all deaths worldwide. More than one-third of these deaths occur in middle-aged adults. In recent decades, an increased prevalence of CVD ashore has been observed owing to demographic changes and to the growing importance of unhealthy life-style related cardiac risk factors (such as smoking, high-fat diet and insufficient physical activity). All these factors determine the cardiovascular risk both in the general population and among seafarers. Prospectively, the expected advancing average age of seafarers will raise the CVD risk considerably.

The diagnosis and treatment of crew members at sea rely on the actions and knowledge of the nautical officers who are in charge of medical care on board. Thus, it is possible that the crew has to manage first-aid treatment on board for several days or even weeks until professional help is available. The options for the treatment of CVD are restricted on ships and not comparable with those ashore. On German-flagged vessels, medication is available for acute chest pain (isosorbide dinitrate, glycerol-trinitrate) and for heart rhythm disorders (metoprolol tartrate, verapamil hydrochloride, adrenaline, atropine) [1]. In total, an improvement of diagnosis and treatment of CVD in seafaring is strongly required $[2,3]$.

\section{CURRENT DEVELOPMENT IN MERCHANT SEAFARING}

In recent decades, a considerable change of the working and living conditions of seafarers have occurred [4]. These changes are characterised by e.g.

- A lower average number of crew members as a consequence of modern ship technique and leading to a higher level of responsibility for each seaman. On average, crew manning has decreased from 30 to 20 seafarers on board container ships within the past 40 years.

- The quick port rotation of vessels with only short stays in port. Furthermore, due to more and more economic loading/ /unloading process, the ship's demurrage in port has been shortened (from 2 or 3 to currently 1 day at maximum).

- Frequently changing crews which may hamper the development of a confidential social system on board. 


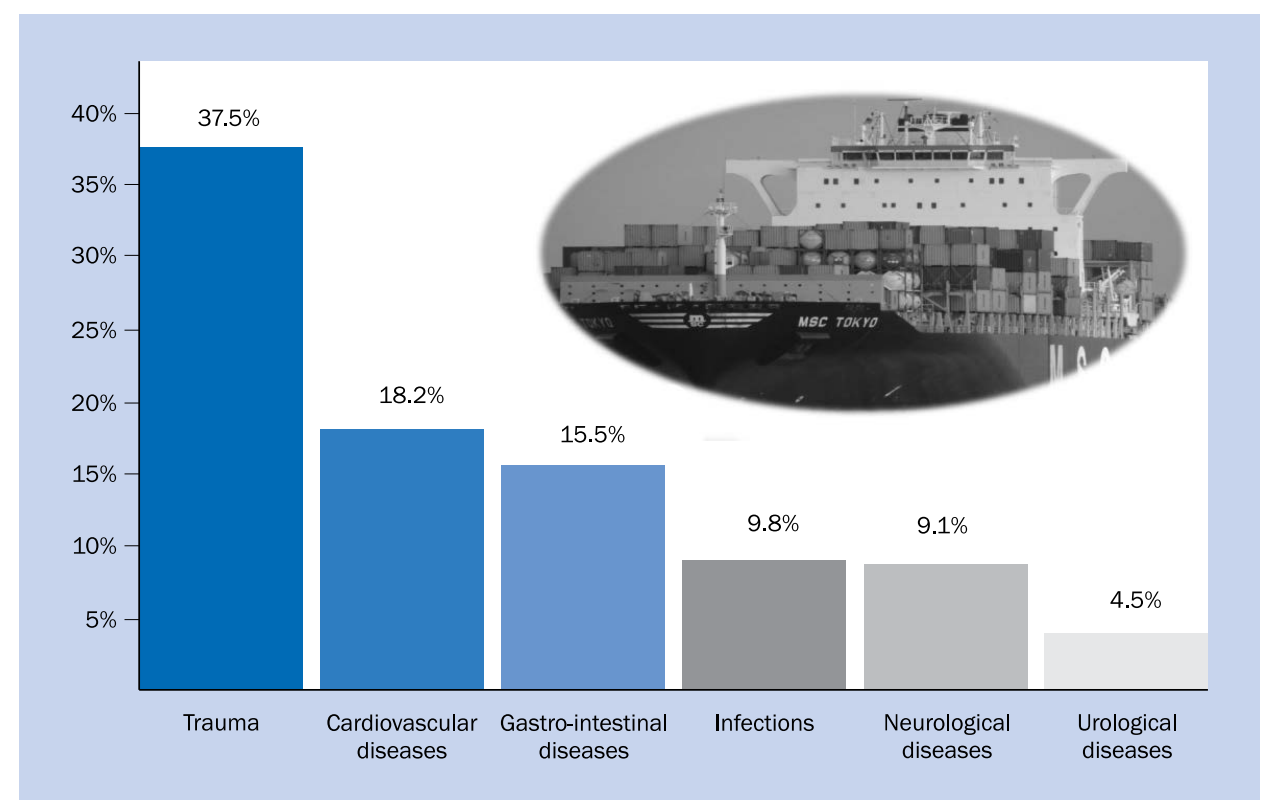

Figure 1. Frequencies (\%) of serious medical emergencies in all types of vessels

In general, up to date the physical and mental stress has increased considerably so that an elevated risk of CVD is also assumed among seafarers.

\section{PREVALENCE OF CVD IN SEAFARERS}

Besides accidents and work-related injuries, severe CVD pose the main cause of death - both in general population from industrialised countries as well as in seafaring population. Various maritime mortality studies revealed CVD mortality from 27 to 45 per 100,000 seafarer-years [5-7]. In the 1980s and 1990s, a British and Danish study on mortality among seamen showed that CVD accounted for $55 \%$ to $70 \%$ of all natural causes of death. An own, so far unpublished, mortality study of German seafarers who had died on board in the time period from 1998 to 2008 also confirmed that the majority of documented seafarer's deaths were related to CVD.

Jaremin and Kotulak [8] performed a retrospective mortality study from 1985 to 1994 based on a population of 11,325 Polish seafarers and deep-sea fishermen with an average age of 50 years (average job duration was 23 years). They found that more than $70 \%$ of the documented mortalities at sea were caused by myocardial infarction (MI); these seafarers consisted of 20 nautical officers or captains, 18 engine room officers, 33 able bodied seamen, 26 crew ranks of the engine room and 9 galley staff members. Prognosis after a cardiac event was also assessed in the latter Polish mortality study. Concerning the same decade, the mortality rate of $\mathrm{MI}$ in Polish seafarers was lower than that in the general male Polish population. This may indicate the expected healthy worker effect among seamen. In this study, the survival after a coronary event at sea, however, was shown to be lower than that ashore since the early (first day) pre-hospital mortality of seafarers after a $\mathrm{Ml}$ at sea was $48 \%$ compared to $20-35 \%$ in the general population. Thus, the authors concluded that the prognosis after $\mathrm{Ml}$ at sea is worse than that ashore. It is assumed that this finding is due to a lack of early intervention with angioplasty or lysis. Further reasons for the worse prognosis after a $\mathrm{Ml}$ at sea might be that the rescuers on board as medical lay persons are often inexperienced, the means of treatment are limited, the rescue/resuscitation action is frequently delayed, and the evacuation ashore is often difficult or impossible [1].

In a recent German survey, 465 nautical officers who participated in the medical refresher course at the Institute for Occupational and Maritime Medicine in Hamburg were interviewed about their experience of serious diseases and accidents on board, which had led to an emergency port call, a course deviation or an evacuation [9]. 133 (28.6\%) seafarers reported on an experience of at least one serious medical emergency at sea during their seafaring time. According to their statements, CVD were the second most frequent cause for serious medical emergencies on board, after trauma (Fig. 1).

With regard to the vessel type, a high number of CVD occurred particularly on passenger liners (29.4\%) with many and frequently older people on board. Besides passenger liners, the occurrence of serious CVD required a course deviation in 10 out of 69 reported cases on container ships [9]. 


\section{RISK FACTORS FOR CVD AMONG SEAFARERS}

Generally, the risk of CVD depends on many factors which can be classified into following groups: non influenceable (genetic factors, family history, sex, age), influenceable, but not directly dependent on conditions aboard (e.g. arterial hypertension, diabetes mellitus, smoking), and influenceable and probably related to conditions aboard (stress, high fat diet, lack of exercise). The seafarer's cigarette consumption as an important CVD risk factor has been repeatedly described to be higher than in the general population $[10,11]$. A recent review of the literature about CVD risk factors covered 18 studies and revealed smoking prevalence between $37.3 \%$ and $72.3 \%$, with a decreasing trend in the 2000s [12].

In a German cross-sectional study, 161 male seafarers employed on German-flagged vessels were interviewed as well as medically examined [2]. In this study the cardiac risk factors, such as high blood pressure (49.7\%), high triglycerides (41.6\%), advanced age (39.8\%), and smoking (37.3\%), predominated. Particularly engine room officers and the galley staff showed a higher risk of CVD assessed by the number of risk factors (median of more than 3 risk factors). Furthermore, officers compared to the crew ranks were characterised by a higher proportion of subjects with more than 3 risk factors.

To assess the risk of CVD, 106 (65.8\%) seamen of the German study were assigned to the group with a lower number of risk factors $(<3)$ and $55(34.2 \%)$ to the group with a higher number of risk factors $(\geq 3)$. In respect of the workload, job duration at sea was associated with at least 3 cardiovascular risk factors after adjusting for age (OR 1.08, $95 \% \mathrm{Cl} 1.02-1.14)$. Working hours on board and average stay, however, did not show any association with the number of risk factors for CVD [2].

At present, ship crews are manned with seamen from various countries. Due to the obviously different basic risk, an assessment of the CVD risk among the multinational seafaring population by applying only one population-specific risk score is not possible. Since the PROCAM population consisted of German workers, exclusively male subjects (5,527 employees aged 35-64 years) [13], this study group was used as a reference population for the examined German seamen.

As seafarers are subjected to biennial medical fitness tests for nautical service, a healthy worker effect is expected in this occupational group. The comparison between the population of seafarers examined in the mentioned German study and that from PROCAM revealed that the seafarers were older and smoked more often. After standardising for age, the German seafarers displayed a similar predicted 10-year risk for coronary heart diseases as the
German reference population of about the same age (57 vs. 56 per 1,000 subjects); taking into account the expected healthy-worker-effect, however, an at least slightly increased coronary risk of the seafarers can be assumed [2, 14].

Several shipboard stress factors, which are assumed to contribute to a higher CVD risk, can only scarcely be reduced (e.g. shift work, noise and vibration, occasional exposure to high temperature during physical effort). Particularly, the influenceable risk factors probably related to conditions aboard are accessible to occupational preventive measures [15].

\section{INFLUENCEABLE SHIPBOARD CVD RISK FACTORS}

\section{STRESS}

Job-related stress poses a contributing risk factor for CVD. Kivimäki et al. [16] observed in their broad meta-analysis of prospective cohort studies, that stress at work was associated with an increased CVD risk by $50 \%$ on average. In general, psychosocial stress aboard is caused by excessive work demands, shift work, external control of work and lack of scope in decision-making [17-19].

The employment in the maritime sector is also associated with specific psychosocial stressors (including long-time separation from the family, mental stress, extremely long working hours, permanent changing crews, reduced duration and quality of sleep on board, irregular working time, and permanent physical impacts such as ship movements, noise and vibration) [20]. Seafaring is known as an occupation related with a high psychophysical stress for crews [17]. Furthermore, restricted leisure time facilities on board often lead to a lack of exercise and consequently to overweight.

Owing to the unique unity of workplace and limited leisure area on board - frequently lasting for months - seafarers are exposed to high stress on board and consequently to a higher CVD risk. A reduction of mentioned shipboard stress can be achieved by organisational measures such as shorter contract durations or increased crew manning.

\section{NUTRITION ON BOARD}

During stays on board over several months, seafarers can scarcely influence the usually unbalanced and highfat diet aboard [21] contributing to high cholesterol, high triglycerides and obesity. The international regulations on nutrition on board are not homogenous, but reflect the flag-state standard. Up to date, only few studies have been comprehensively engaged in food patterns of seafarers; unfortunately, objective examination methods are often missing in these studies. These methods would allow assessing the current food intake and activity-related energy requirements [22]. 
A Croatian study revealed that $75 \%$ of sailors $(n=174)$ were overweight, $80 \%$ showed increased cholesterol values, and $30 \%$ increased blood glucose values [3]. According to a Norwegian study $64 \%$ of examined seafarers were overweight and $23 \%$ of them were estimated as "obese" [23]. A population of US inland waterway merchant marine captains and pilots displayed a high prevalence of obesity (61\%), high triglycerides (42\%), low high density lipoprotein cholesterol (47\%), high blood pressure (42\%), high fasting glucose (22\%) and 3 or more features of the metabolic syndrome (39\%) [24].

A recent survey [25] covering 104 German seafarers revealed that:

- 95\% rated the food on board as "very important" or "important" for their level of job satisfaction and well-being in their daily routine;

- approximately $80 \%$ stated that they would prefer to eat healthier;

- "fresh products, native food, variety and quality" were most often missed in shipboard provision;

- $20 \%$ took dietary supplements like pills (2/3 of them were Filipinos). The common practice of seafarers to use vitamin supplements probably is of limited value concerning CVD risk reduction.

To assess the relevance of cardiovascular risk factors due to the seafarers' eating habits, objective procedures such as blood analysis or ergospirometric stress tests are required. There is a need for future comprehensive maritime research studies on board to estimate the eating habits among seafarers [22]. Furthermore, it is assumed that multicomponent health promotion intervention programs (e.g. health cooking courses) has the potential to change seafarers' health behaviour and health parameters [14].

\section{LACK OF EXERCISE}

Reduced recreational opportunities on board often lead to a lack of exercise which also favours overweight. Older examinations demonstrated an average energy consumption of seamen in the merchant fleet between 3000-3500 kcal [26]. It has been assumed that the energy consumption of seafarers has decreased in the recent decades due to technical progress in ship operation [25].

A Norwegian survey revealed that $70 \%$ of asked seafarers did sports twice or more per week when at home, whereas only $39 \%$ exercised on board [27]. According to this study, the seafarers preferred strength training more often on board than at home. The highest motivation for doing sports was preventing illness and injury, to have a pleasant atmosphere in a well-equipped fitness room and keeping their weight under control.

The possibilities of exercising on board outside working hours are reduced. Therefore, fitness rooms are nowadays established on large merchant ships and mostly equipped with weights, punching bags, treadmills or stationary bikes. According to the authors' experiences, however, these physical leisure facilities were only used by less than $20 \%$ of the crews on a regular basis.

\section{IMPROVEMENT IN DIAGNOSIS OF THE HEART RHYTHM}

The first clinical signs of CVD are often unspecific thoracic symptoms. To improve reliability of diagnosis in patients with these symptoms, a telemedical transmitted electrocardiogram (ECG) can provide an important information, especially in case of potentially arrhythmic heart diseases. Therefore, Germany as the first country worldwide regulated by law that "AEDs including ECG display and telemedical transmission of 1-lead-ECG to the TMAS in Cuxhaven" have to be available on board of merchant ships by September 2012 at the latest [28, 29].

A telemedical transmitted ECG is of great value to know the current heart rhythm, to monitor a seafarer's heart rhythm over several days, to improve survival rate in resuscitation and to objectify the death of a subject on board. Among practitioners in maritime medicine, the relevance and the cost-benefit ratio of semi-automatic defibrillators are controversially discussed.

\section{RECOMMENDED MEASURES FOR REDUCTION OF CARDIOVASCULAR RISKS}

Up to now, it is a challenge for maritime health experts to reduce the CVD risk and to improve the survival after cardiac events at sea. For this purpose, a joint action [1] is necessary of:

- the shipping companies (e.g. by provision of suitable technical devices, telemedicine or ECG, by a satisfactory offer of shipboard exercise possibilities, a more balanced diet, by provision of sufficient sleeping and resting time of the whole crew and by avoidance of extreme overtime hours);

- the ship masters (e.g. by active motivation of his crew to do more sports and by organisation of health information campaigns);

- the medical refresher courses for nautical officers (e.g. to train them in the treatment of CVD, to raise the seafarer's awareness about their individual risk for CVD and to advise them on prevention). The teaching content of these courses are determined in national schedules and focused on diagnosis and treatment of ill or injured seafarers at sea. However, the prevention of diseases, especially of CVD, is scarcely considered in the schedules of these courses;

- the seafarers themselves (e.g. by self-observation of their health and eating habits, by holding responsibility for their health promotion, and by changes of an unhealthy life-style, such as smoking and a lack of exercise). 


\section{REFERENCES}

1. Oldenburg M. Cardiovascular disease. Textbook of maritime medicine. Haukeland University Hospital, Haukeland 2013.

2. Oldenburg M, Jensen HJ, Latza U, Baur X. Coronary risks among seafarers aboard German-flagged ships. Int Arch Occup Environ Health 2008; 81: 735-741.

3. Pancic M, Ricka-Zauhar Z, Blazevic M. Analysis of risk factors and assessment of exposure to coronary diseases in seamen. RijekaCroatia, 8-13 May 2005. Book of abstracts. Rijeka 2005: 11.

4. Oldenburg $\mathrm{M}$, Jensen $\mathrm{HJ}$. Merchant seafaring: a changing and hazardous occupation. Occup Environ Med 2012; 69: 685-688.

5. Roberts SE. Occupational mortality in British commercial fishing, 1976-1995. Occup Environ Med 2004; 61: 16-23.

6. Hansen HL, Pedersen G. Influence of occupational accidents and deaths related to lifestyle on mortality among merchant seafarers. Int J Epidemiol 1996; 25: 1237-1243.

7. Roberts SE. Mortality from disease among seafarers in British merchant shipping (1976-1995). Int Marit Health 2002; 53: 43-58.

8. Jaremin B, Kotulak E. Myocardial infarction (MI) at the work-site among Polish seafarers. The risk and the impact of occupational factors. Int Marit Health 2003; 54: 26-39.

9. Oldenburg M, Rieger J, Sevenich C, Harth V. Nautical officers at sea: emergency experience and need for medical training. J Occup Med Toxicol 2014; 9: 19.

10. Kirkutis A, Norkiene S, Griciene P, Gricius J, Yang S, Gintautas J. Prevalence of hypertension in Lithuanian mariners. Proc West Pharmacol Soc 2004; 47: 71-75.

11. Hansen H, Dahl S, Bertelsen B, Brix J. Lifestyle, nutritional status and working conditions of Danish sailors. Travel Med Int 1994; 12: 139-143.

12. Pougnet R, Pougnet $L$, Lodde $B L$ et al. Cardiovascular risk factors in seamen and fishermen: review of literature. Int Marit Health 2013; 64: 107-113.

13. Hense HW, Schulte H, Lowel H, Assmann G, Keil U. Framingham risk function overestimates risk of coronary heart disease in men and women from Germany: results from the MONICA Augsburg and the PROCAM cohorts. Eur Heart J 2003; 24: 937-945.

14. Hjarnoe L, Leppin A. Health promotion in the Danish maritime setting: challenges and possibilities for changing lifestyle behavior and health among seafarers. BMC Public Health 2013; 13: 1165.

15. Filikowski J, Rzepiak M, Renke W, Winnicka A, Smolinska D. Selected risk factors of ischemic heart disease in Polish seafarers. Preliminary report. Int Marit Health 2003; 54: 40-46.
16. Kivimaki M, Virtanen M, Elovainio M, Kouvonen A, Vaananen A, Vahtera J. Work stress in the etiology of coronary heart disease: a meta-analysis. Scand J Work Environ Health 2006; 32: 431-442.

17. Jeżewska M, Leszczyńska I, Jaremin B. Work-related stress at sea self estimation by maritime students and officers. Int Marit Health 2006; 57: 66-75.

18. Karasek R, Brisson C, Kawakami N, Houtman I, Bongers P, Amick B. The Job Content Questionnaire (JCQ): an instrument for internationally comparative assessments of psychosocial job characteristics. J Occup Health Psychol 1998; 3: 322-355.

19. Greiner B, Krause N. Expert-observer assessment of job characteristics. In: Schnall P, Belkic K, Landsbergis P, Baker D eds. The workplace and cardiovascular disease. Hanley \& Belfus, Inc., Philadelphia 2000: 175-183.

20. Oldenburg M, Jensen HJ, Latza U, Baur X. Seafaring stressors aboard merchant and passenger ships. Int J Public Health 2009; 54: 96-105.

21. Babicz-Zielinska E, Zabrocki R. Assessment of nutrition of seamen and fishermen. Rocz Panstw Zakl Hig 1998; 49: 499-505.

22. Oldenburg M, Harth V, Jensen HJ. Overview and prospect: food and nutrition of seafarers on merchant ships. Int Marit Health 2013; 64: 191-194.

23. Hoeyer JL, Hansen H. Overweight among nordic male seafarers. 8th International Symposium of Maritime Health. Rijeka, Croatia, 8-13 May 2005. Book of abstracts. Rijeka 2005: 27.

24. Scovill SM, Roberts TK, McCarty DJ. Health characteristics of inland waterway merchant marine captains and pilots. Occup Med 2012; 62: 638-641.

25. Wittkowski R. Nutrition onboard seagoing merchant vessels. Fachbereich Seefahrt. Jadehochschule, Elsfleth 2011.

26. Zorn E. The seafare's food. In: Goethe WHG, Watson EN, Jones DT eds. Handbook of nautical medicine. Springer, Berlin 1984: 143-151.

27. Geving IH, Jorgensen KU, Thi MS, Sandsund M. Physical activity levels among offshore fleet seafarers. Int Marit Health 2007; 58 : 103-114.

28. Oldenburg M, Baur X, Schlaich C. Assessment of three conventional automated external defibrillators in seafaring telemedicine. Occup Med 2012; 62: 117-122.

29. Oldenburg M, Baur X, Schlaich C. Implementation of automated external defibrillators on merchant ships. J Travel Med 2011; 18 : 233-238. 